\title{
Night temperature and number of nodes and flowering of the main stem of glasshouse cucumber (Cucumis sativus L.)
}

\author{
P. J.A. L. de Lint and G. Heij \\ Glasshouse Crops Research and Experiment Station, Naaldwijk, Netherlands
}

Accepted: 11 January 1982

Key-words: nodes, main stem, earliness, flower axils, glasshouse, cucumber, night temperature, season, planting date

\section{Summary}

Four plantings of glasshouse cucumber were grown at three night temperatures. Data observed on number of nodes per stem, number of flowers per stem, and earliness and rates of flowering are presented and discussed. The number of nodes per stem increases with lower night temperature. The relation is asymptotic towards full suppression of elongation near $11^{\circ} \mathrm{C}$. With later planting dates, internodes are longer. Plants in the crop have longer internodes than the ones on the outside. These two observations cannot be explained as an effect of light only.

The number of flowers per stem is determined by the number of nodes with flowers and by the number of flowers per node. The number of flowers per node increases towards the top of the stem. Later planting results in more flowers per node over the whole length of the stem. Night temperature has only little effect on the number of flowers per node.

At $16^{\circ} \mathrm{C}$ night temperatures the highest figures for flowers per node are found. Earliness of flowering of the first flowers per axil increases with higher night temperature and so does the rate of flowering. Later planting only partly results in later flowering.

The position of plants in the crop has no influence on earliness of flowering. The number of flowers on plants deeper in the crop is somewhat lower than on outer plants, mainly because of lesser nodes.

\section{Introduction}

With increasing prices of energy it seems worthwile to specifically enlarge knowledge about the relation between production curve, temperature and planting date for glasshouse cucumber cropping.

In winter, most of the heating energy for glasshouse crops is consumed during 


\section{P. J. A. L. DE LINT AND G. HEIJ}

night hours, and since cucumber in the Netherlands is grown under rather high temperatures (night $16-20^{\circ} \mathrm{C}$ ), an experiment was set up to investigate the effects of lower and of varying night temperatures on cucumber (van de Vooren et al., 1978).

The experiment was carried out in the climate glasshouse of the Glasshouse Crops Research and Experiment Station at Naaldwijk (van de Vooren, 1975, 1977; van de Vooren \& Koppe, 1975).

Data on stem length development and on opening of the flowers along the main stem of the three steady night temperature treatments are reviewed. Except for some rather early publications about the characteristics for quite different varieties (Hori \& Arai, 1971; Miller \& Ries, 1958), there seems to be little information on flowering in cucumber and with respect to night temperature. (See for more literature Lorenz (1980) and Acta Horticulturae Vol. 118.)

\section{Materials and methods}

Cucumber plants, cv. Farbio, a female flowering variety that develops parthenocarpic fruit, were planted in the climate house about 30 days after sowing. Four plantings were performed, with fortnightly intervals, on 13 and 27 December 1976, and on 10 and 24 January 1977. Plants were placed in rows. Distance between rows was $1.6 \mathrm{~m}$. In the row, spacing between plants was $0.5 \mathrm{~m}$. Night temperatures used were 12,16 and $20^{\circ} \mathrm{C}$. These differences of night temperature were carried on until 1 April 1977. The switch from night to day was $1 / 2$ hour before sunrise and from day to night it was at sunset. $\mathrm{CO}_{2}$ concentrations were controlled during daytime at $0.1 \%$.

From all plants flower buds and lateral shoot buds were pruned up to the 10th axil (about $0.8 \mathrm{~m}$ above border soil level). The main stem was stopped at the level of the supporting wire ( $2.2 \mathrm{~m}$ above border soil level). Shoot buds were taken out all the way along the main stem except for the two or three highest ones.

This pruning procedure is generally adopted by glasshouse cucumber growers in the Netherlands. Flowering was registered three times a week. Fruits were initially harvested three times a week, but after three weeks only twice weekly. Fresh weight and length were determined for each individual fruit on the data of harvest. Calculations are presented on plant heights in number of nodes in the main stem when stopped at the height of the wire, and on flowering. Data are obtained from five plants per treatment and the experiment was in threefold. Data on numbers of fruits and fruit development, and on abortion of flowers of the same plants are presented elsewhere (Heij, 1981; Heij \& de Lint, 1982; de Lint \& Heij, in preparation; de Lint \& Heij, 1981). 


\section{Results $^{1}$}

\section{Flower axils}

Stem height was limited to the height between border soil and supporting wire, at about $2.2 \mathrm{~m}$, by pinching the plant tips. As a result of temperature treatment and planting date the node numbers per plant were different. As a consequence the number of nodes with flowers was different between plots. Since flower initials were removed from the bottom 10 axils of each plant, the number of nodes with flowers is determined by the nodes from number 11 upwards till the stopping position at the top. The total material comprises 180 plants with 2547 flower axils.

Effects of the experimental lay-out can be judged from the data in Table 1, showing the differences between parallels and the effect of the position of the plants on the row.

In Fig. 1 the effects of the experimental factors, viz night temperature and planting date, on the number of flower axils per plant, are presented as mean values over the three replicates and rows of five plants. The data show that plants have less nodes when deeper in the row. The effect is gradual and is between 1 and 9 some 1.5 nodes. There is almost no difference in number of nodes between the first two plantings (13 and 27 December). The effect of shifting to still later plantings, however, is quite considerable with respect to the number of nodes per plant. Stems have some 3 nodes less per 4 weeks later planting.

Night temperature has a most striking effect on the number of nodes. Lower night temperatures clearly cause increasingly stunted growth. The curve from $20^{\circ} \mathrm{C}$ via $16^{\circ} \mathrm{C}$ to $12{ }^{\circ} \mathrm{C}$ night temperature seems to reach an asymptotic value near $11{ }^{\circ} \mathrm{C}$, suggesting the development of infinite leaf numbers at still lower temperatures.

\section{Flowers}

Flowers that had opened were registered three times weekly for practically all

Table 1. Glasshouse cucumber 1977. Number per plant of axils with flowers on the main stem (see text), for three steady night temperatures $\left(20,16\right.$ and $\left.12^{\circ} \mathrm{C}\right)$ and four planting dates $\left(I=13-12-^{-} 76\right.$; II $=27-12-' 76$; III $=10-1-' 77$, and IV $=24-1-^{\prime} 77$ ). Data are averages for rows of five plants, in three parallels.

\begin{tabular}{lllllll}
\hline Parallel & \multicolumn{6}{l}{ Plant number } \\
\cline { 2 - 7 } & 1 & 3 & 5 & 7 & 9 & $\overline{\mathbf{m}}$ \\
1 & 15.6 & 15.3 & 14.3 & 14.2 & 13.8 & 14.6 \\
2 & 13.5 & 13.9 & 14.5 & 13.8 & 12.8 & 13.7 \\
3 & 15.1 & 14.5 & 14.2 & 13.5 & 13.3 & 14.1 \\
$\overrightarrow{\mathrm{m}}$ & 14.7 & 14.6 & 14.3 & 13.8 & 13.3 & 14.2 \\
\hline
\end{tabular}

1 Tables with original figures per plant are available on request. 


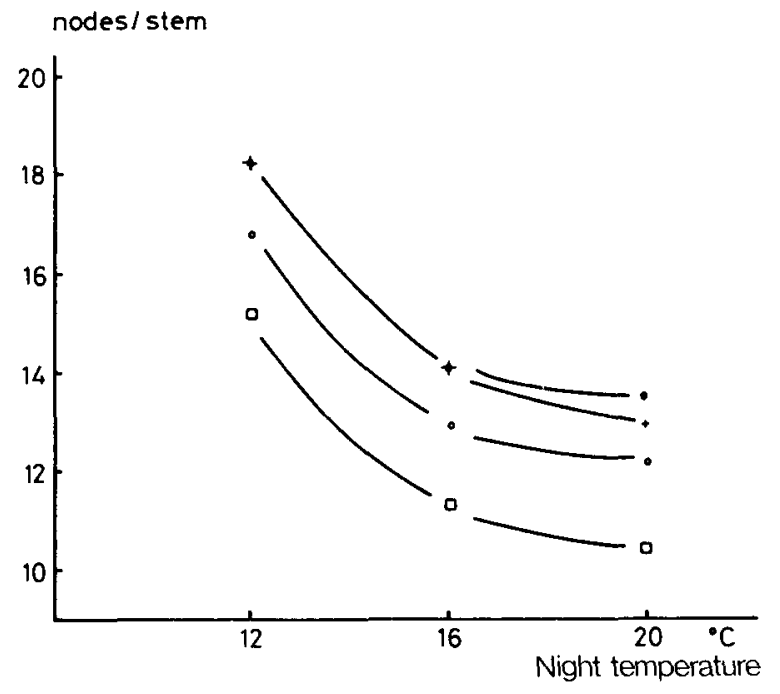

Fig. 1. Glasshouse cucumber 1977. Effect of constant night temperature on number of nodes per stem, when stems are decapitated at the height of the supporting wire (some $2.2 \mathrm{~m}$ above soil level). Curves represent data for four planting dates, viz.: $13-12-76 ;+: 27-12-$ '76; O: 10-1-'77, and $\square: 24-1-' 77$.

Table 2. Glasshouse cucumber 1977. Number per plant of flowers on the main stem.

A (top): three parallels $(1,2,3)$, for five plant positions on a row of ten plants $(1 \rightarrow 9=$ into the crop). Data are averages over four plantings and three steady night temperatures, taken from Table 2B.

B (bottom): three steady night temperatures $\left(20,16\right.$ and $12^{\circ} \mathrm{C}$ ), and four plantings (I, II, III and IV: see Table 1). Data are averages for rows of five plants, in three parallels.

\begin{tabular}{|c|c|c|c|c|c|c|}
\hline \multirow[t]{2}{*}{ Parallel } & \multicolumn{6}{|c|}{ Plant number } \\
\hline & 1 & 3 & 5 & 7 & 9 & $\overline{\mathrm{m}}$ \\
\hline 1 & 26.4 & 24.3 & 20.3 & 20.1 & 18.6 & 22.0 \\
\hline 2 & 17.2 & 19.2 & 18.8 & 17.6 & 16.8 & 17.9 \\
\hline 3 & 21.8 & 21.2 & 20.2 & 18.5 & 18.7 & 20.1 \\
\hline$\overline{\mathrm{m}}$ & 21.7 & 21.6 & 19.8 & 18.7 & 18.0 & 20.0 \\
\hline \multirow{2}{*}{$\begin{array}{l}\text { Planting } \\
\text { date }\end{array}$} & \multicolumn{4}{|c|}{ Night temperature $\left({ }^{\circ} \mathrm{C}\right)$} & & \\
\hline & 20 & 16 & 12 & $\overline{\mathrm{m}}$ & & \\
\hline I & 17.6 & 20.8 & 22.0 & 20.1 & & \\
\hline II & 17.2 & 21.5 & 23.7 & 20.8 & & \\
\hline III & 16.6 & 20.7 & 20.8 & 19.4 & & \\
\hline IV & 15.8 & 20.5 & 22.7 & 19.6 & & \\
\hline $\overrightarrow{\mathrm{m}}$ & 16.8 & 20.9 & 22.3 & 20.0 & & \\
\hline
\end{tabular}


flowers along the main stems. All axils contained one and some two or more flowers. The total amount of flowers registered was 3597 on 180 plants. The total number of flowers per plant was different for the plant positions on the row and the three parallels carried slightly different amounts of flowers, as can be seen from Table $2 \mathrm{~A}$.

Of the experimental factors, planting date practically had no influence on the total number of flowers per stem. Night temperature, however, gave quite different numbers. Table $2 \mathrm{~B}$ shows these effects. With lower night temperature, more flowers are produced. (See also Fig. 2 (a, b, c and d, e, f, g), in which these results are presented for the individual treatments.)

Of course, the higher number of flowers with lower night temperatures is connected with the higher number of nodes with lower night temperature. Therefore it seems worthwile to calculate the amounts of flowers per node for the various treatments. In Fig. 3 ( $a, b, c$ and d, e, f, g) the number of flowers per axil for the various night temperatures and the planting dates are presented. It will be seen that, irrespective of night temperature, flowers are more numerous towards higher axils. A difference between night temperatures is that with $16^{\circ} \mathrm{C}$ more flowers per axil have developed over the whole length of the stem than with either 20 of $12^{\circ} \mathrm{C}$. From Fig. 3 it will be also evident that with later planting dates, equally for the three night temperatures, the plants produced more flowers per axil than earlier planted ones.

\section{Flowering}

The rate of flowering, as it is observed from the flowering dates of individual flowers for the three night temperature treatments and for the four plantings is presented in Fig. 4.

With Fig. 4 (e, f, g), flowering is presented per temperature treatment for each planting. The curves are smoothly drawn through the original points. It may be possible to study these, in part rather systematic, deviations somewhat further in connection with the analysis of other data collected on the same plant material, such as leaf initiation and leaf length growth. This information will be published later.

For the moment it seems only justified to compare the overall effects of the treatment in earliness and maximum rates of flowering. From Fig. 4 (a, b, c, d) it will be clear that lower night temperature results in delayed flowering. Also, flowering is considerably extended in time. The maximum rate of flowering is somewhat lower with lower night temperature. These effects are found for the four plantings, but the effect of temperature is smaller with later plantings. Fig. 4 (a, b, c, d) shows that for each night temperature with later planting the maximum intensity of flowering increases and that the duration of the period of flowering is reduced.

Table 3 presents a crosssection at two selected positions on the main stem for the moment of flowering on these nodes. Table 3 shows that the average day of flowering for first flowers in the node positions 13 and 14, and 18 and 19 is later with lower night temperature. From Table 3 it can be further seen that these 


\section{P. J. A. L. DE LINT AND G. HEIJ}
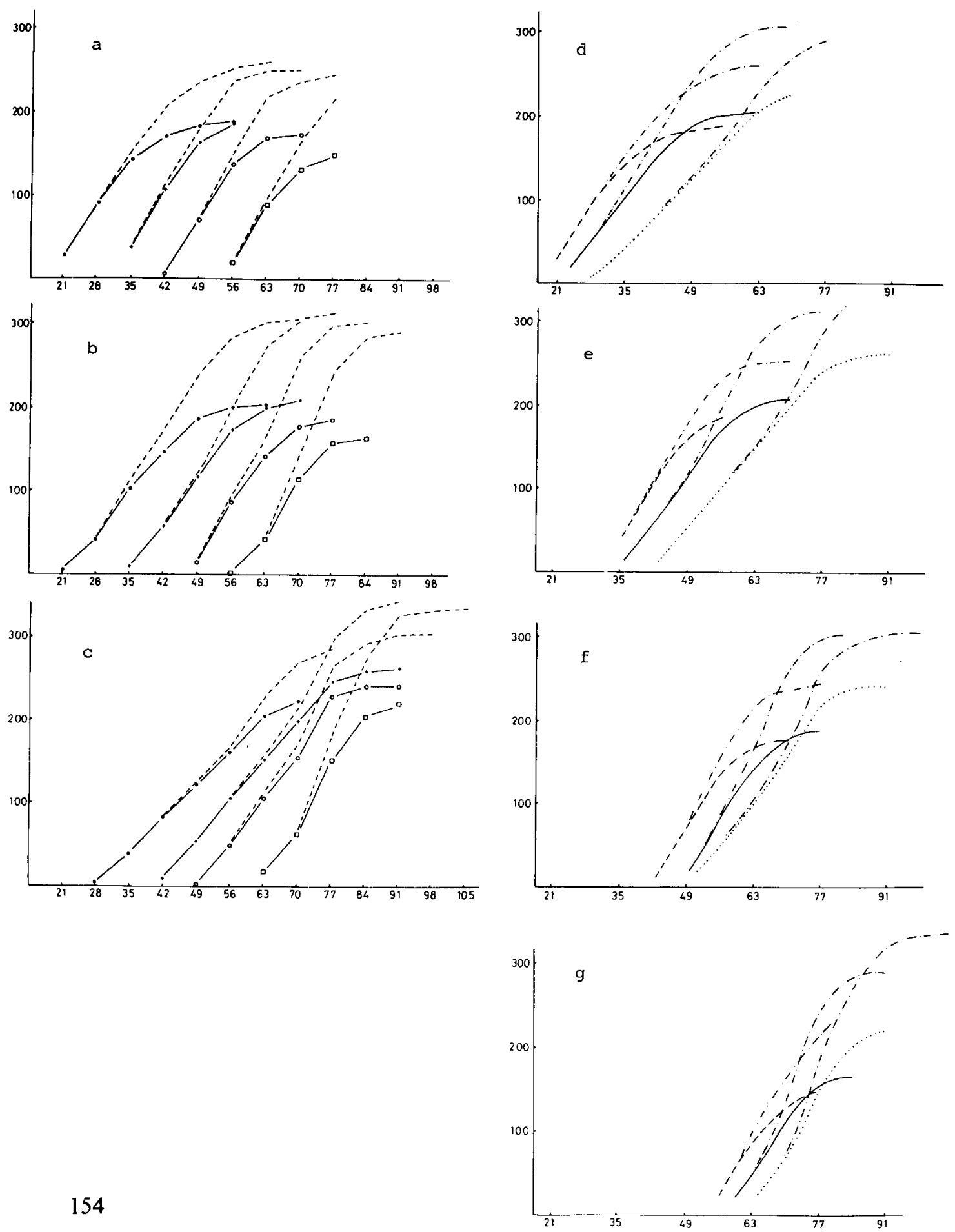
Table 3. Glasshouse cucumber 1977. Average date of flowering in axils 13 and 14, and in axils 18 and 19 of the main stem, for three steady night temperatures $\left(20,16\right.$ and $12^{\circ} \mathrm{C}$ ) and for plantings (IIV: See Table 1). To the right: average difference in date of flowering between axils 13 and 14, and axils 18 and 19 as presented in $A$, for the three night temperatures and the four plantings.

\begin{tabular}{|c|c|c|c|c|c|c|c|c|c|c|}
\hline \multirow[t]{3}{*}{ Planting } & \multirow{3}{*}{$\begin{array}{l}\text { Night temperature } \\
\left({ }^{\circ} \mathrm{C}\right) \rightarrow\end{array}$} & \multicolumn{9}{|c|}{ Axil number } \\
\hline & & \multicolumn{3}{|c|}{$13 / 14$} & \multicolumn{3}{|c|}{$18 / 19$} & \multicolumn{3}{|c|}{ average differenc } \\
\hline & & 20 & 16 & 12 & 20 & 16 & 12 & 20 & 16 & 12 \\
\hline I & & 24 & 29 & 35 & 32 & 38 & 46 & 8 & 9 & 11 \\
\hline II & & 37 & 42 & 49 & 45 & 51 & 59 & 8 & 9 & 10 \\
\hline III & & 48 & 53 & 56 & 55 & 61 & 65 & 7 & 8 & 9 \\
\hline IV & & 60 & 64 & 69 & 65 & 71 & 75 & 5 & 7 & 6 \\
\hline$\overline{\mathrm{m}}$ & & 42 & 47 & 52 & 49 & 55 & 61 & & & \\
\hline
\end{tabular}

Table 4. Glasshouse cucumber 1977. Average date of flowering in axils 13, 14 en 18, 19 of the main stem, for plants in five positions on a row of 10 plants $(1=$ outside crop), and for four plantings (IIV: See Table I0.

\begin{tabular}{|c|c|c|c|c|c|c|}
\hline Planting & Plant number $\rightarrow 1$ & 3 & 5 & 7 & 9 & $\overline{\overline{\mathrm{m}}}$ \\
\hline I & 35 & 34 & 34 & 35 & 33 & 34 \\
\hline II & 46 & 47 & 49 & 47 & 47 & 47 \\
\hline III & 56 & 57 & 57 & 57 & 56 & 57 \\
\hline IV & 67 & 68 & 67 & 68 & 67 & 67 \\
\hline$\overline{\mathrm{m}}$ & 51 & 52 & 52 & 51 & 51 & \\
\hline
\end{tabular}

differences in fact are due to differences in the flowering rates. The number of days between flowering of axils 13 and 14 , and of axils 18 and 19 is longer with lower night temperature. However, this effect is weaker for later plantings.

Table 4 , finally, shows that day of flowering of axils $13 / 14$ and $18 / 19$ is not dependent on the position of plants on the row.

\section{Discussion and conclusions}

The data on node numbers per stem can be discussed as a measure for internode lengths, because of the fact that eventually all stems were given the same length, as they were all pinched at wire height.

The lower number of nodes present onto the wire in plants of later plantings is

Fig. 2. Glasshouse cucumber 1977. Number of flowers per stem on dates of flowering; cumulative totals of all flowers (upper curves) and of first flowers per axil only (lower curves).

a, b, c: night temperature 20,16 and $12^{\circ} \mathrm{C}$ respectively. Planting dates: $13-12-' 76 ;+: 27-12-{ }^{-} 76$;

O: 10-1-'77 and $\mathrm{D:}$ :24-1-'77. All flowers - - - .

d, e, f, g: planting date 13-12-'76, 27-12-'76, 10-1-'77 and 24-1-'77 respectively. Night temperatures: $--20^{\circ} \mathrm{C} ;-16^{\circ} \mathrm{C}$ and $\ldots 12^{\circ} \mathrm{C}$. All flowers....- . 
P. J. A. L. DE LINT AND G. HEIJ
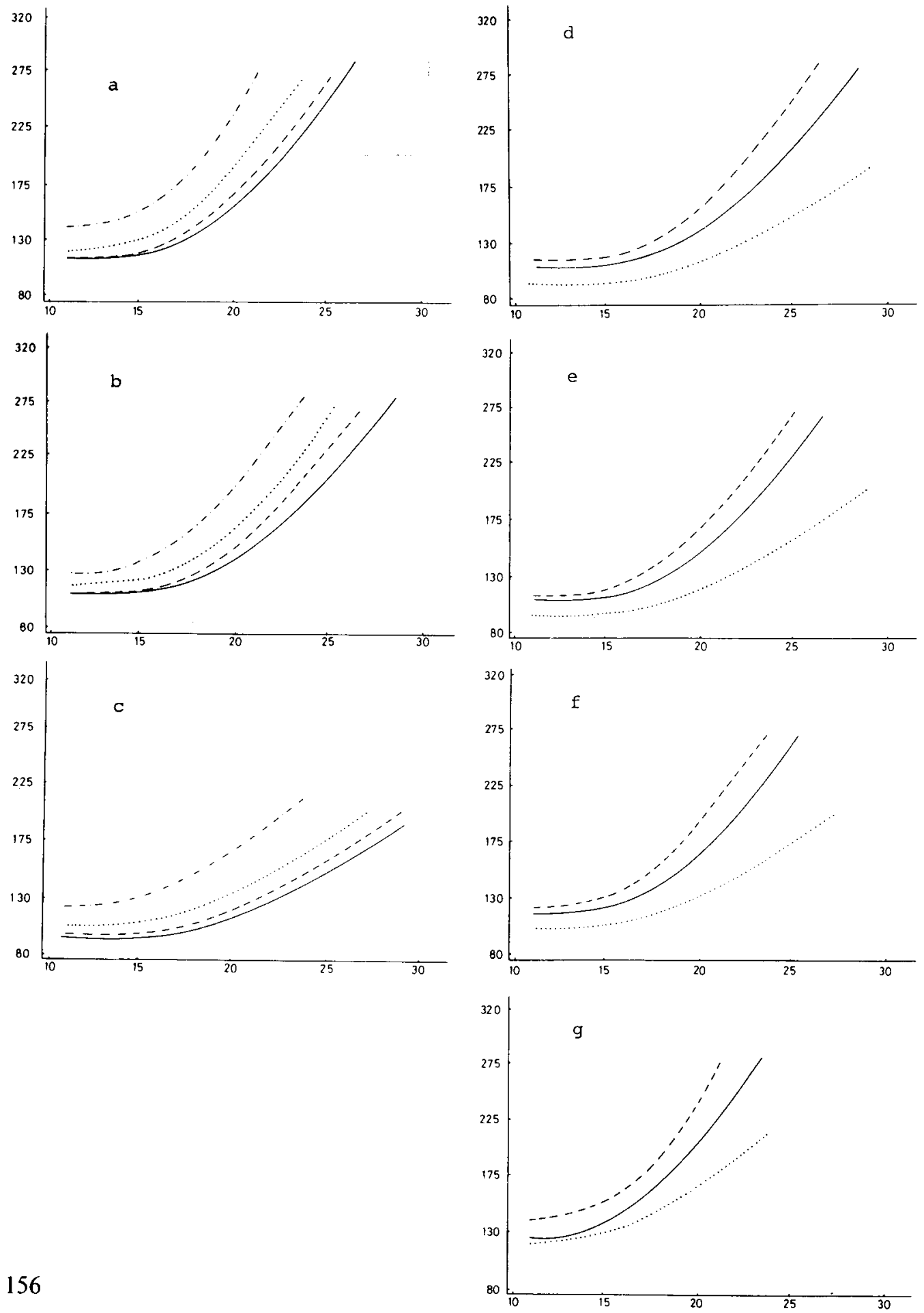
very intriguing, since one would expect precisely the reverse. One is used to reasoning that later plantings, receiving more sunlight, should be heavier, sturdier and of better quality, thus having shorter internodes. Earlier plants should be thin and elongated. The data presented (Fig. 1), however, show that earlier plants have shorter internodes. This would indicate that early plants are not really elongated. Evidently, first of all they are small and thus relatively short. On top of being small they may be thin as well, but according to the data this is clearly a secondary characteristic. According to the data on the effect of night temperature (Fig. 1), extrapolation of the curve for the relation between night temperature and numbers of nodes leads to the conclusion that the variety of cucumber used in this experiment can be supposed to bear infinite numbers of leaves till the wire, or that it will develop rosettes at night temperature values near and below $11^{\circ} \mathrm{C}$. At $12^{\circ} \mathrm{C}$ nights, development at the shoot apex was perfectly normal, except for the reduced length growth of the internodes.

Contrary to the effect of planting date on the elongation of the internodes, the effect of plant position on the row is according to expectation: plants deeper in the crop, nearer to the inner glasswall of the compartment, in a more shaded position, have less nodes below the wire and thus have longer internodes. Clearly, the observed contradiction in these two responses needs further study, especially so, since earliness of flowering is not influenced by the plant position on the row (Table 4).

Numbers of flowers developed per stem are the product of number of nodes and average number of flowers per axil (Fig. 1 and 2). Both aspects are influenced by the experimental factors applied, as demonstrated by the data. With $12{ }^{\circ} \mathrm{C}$ nights, for example, plants produced more flowers per stem than with $16^{\circ} \mathrm{C}$. This effect, however, is solely due to the larger number of nodes on the $12^{\circ} \mathrm{C}$ plants. In fact, the average number of flowers per node was slightly higher for $16^{\circ} \mathrm{C}$. So, lower night temperatures do not intensify generative differentiation. Although the difference is small, rather the contrary seems to be the case.

Planting date, on the other hand, has almost no influence on total flower numbers per stem. Later plantings thus are much more generative in terms of flowers per axil.

The observation that, irrespective of planting date, the amount of flowers per stem is constant, must be discussed in terms of duration of flowering per stem, or as flowering intensity. The combination of these two data will determine the possibilities of individual flowers to develop succesfully into harvestable fruit. The same reasoning will have to be used when discussing the effects of night temperature on numbers of flowers per stem and the duration of flowering. As is

Fig. 3. Glasshouse cucumber 1977. Number of flowers on the main stem per axil $(100=1$ flower/ axil) on axil number.

a, b and c: night temperature 20,16 and $12^{\circ} \mathrm{C}$ respectively. Planting dates: $-13-12-76$; - - $27-12-76 ; . . .10-1-77$, and $-.-.-.24-1-77$.

d, e, f and g: planting date 13-12-76, 27-12-76, 10-1-'77 and 24-1-'77 respectively. Night temperatures: $-20^{\circ} \mathrm{C},--16^{\circ} \mathrm{C}$ and $\ldots 12^{\circ} \mathrm{C}$. 


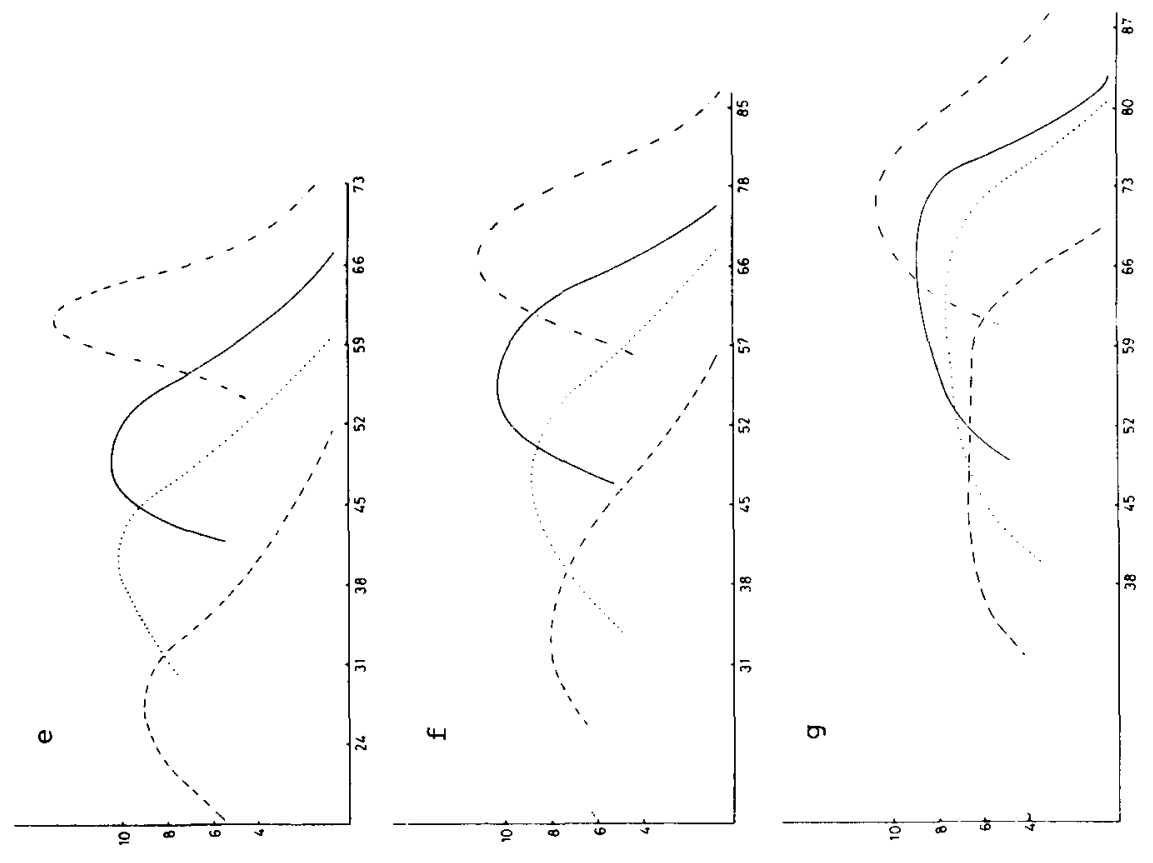

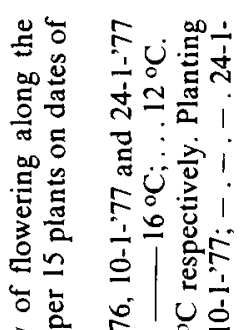

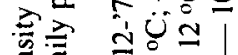

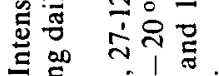

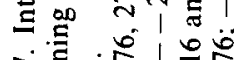

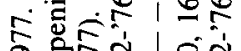

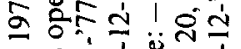

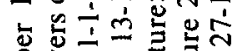
है

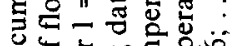

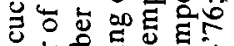

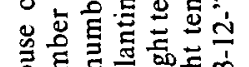

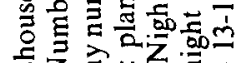

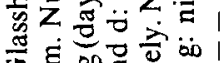

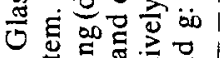

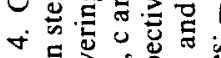

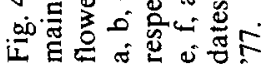

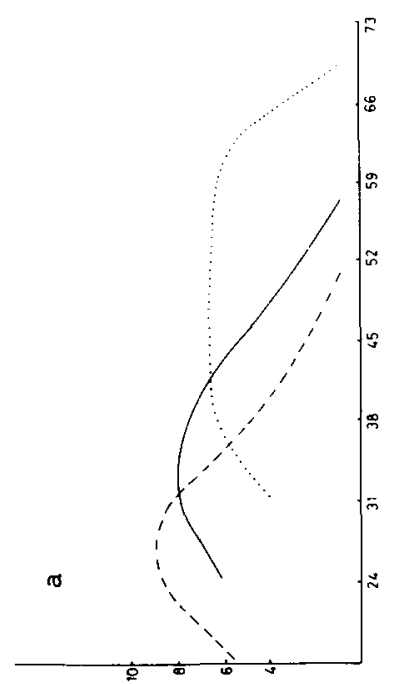

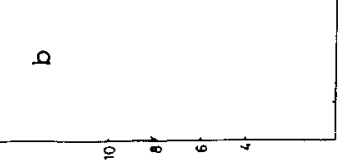

U
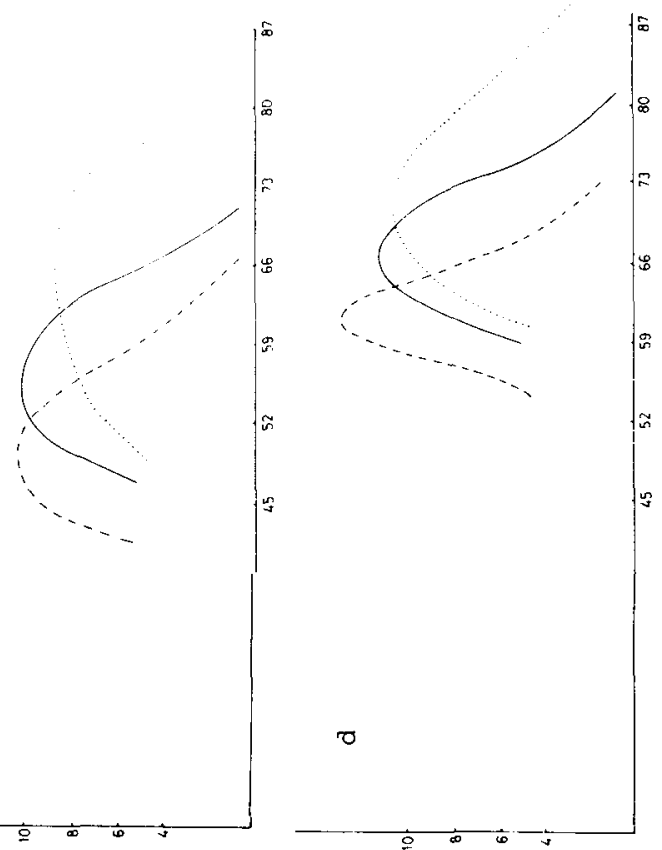

Neth. J. agric. Sci. 30(1982) 
shown (Fig. 4), the average rate of flowering for each treatment rises to a maximum and then declines again. The first rise of the curves is due to the combined effect of differences in earliness of flowering between plants, mainly between parallel plots (it was only two or three days between plants in the rows), and the flowering of second and third flowers of individual nodes that usually flower some 10 days later than the first ones. For this reason it is necessary to distinguish effects of treatments on earliness and rate of flowering, between the flowering data of the first flowers and second and third flowers of the various axils. Thus, data for first flowers only were used for the calculation of the "crosssection' through flowering, presented in Tables 3 and 4 for the stem section between axils $13 / 14$ and $18 / 19$.

From these data it is clear that flowering is speeded up considerably with later planting; 14 days later planting results in only 10 days later flowering (for the first planting it is 13 days). Night temperature has strong effects on flowering. With lower night temperature the rate of flowering is low, and the duration is long. These two aspects result logically from the development of the extra long stem in node numbers the first flowers of which all flower in succession, and of the low degree of secondary flowering that for most of the time takes place simultaneously.

Implications with respect to flower abortion and fruit development of the effects of night temperature and planting date on flowering will be discussed in two other papers (Heij \& de Lint, 1982; de Lint \& Heij, in preparation).

\section{References}

Heij, G., 1981. Glasshouse cucumber, stem elongation and earliness of fruit production as influenced by temperature and planting date. Acta Hort. 118: 105-121.

Heij, G. \& P. J. A. L. de Lint, 1982. Night temperature and fruiting of glasshouse cucumber. (Cucumis sativus L.). Neth. J. agric. Sci. 30: 137-148.

Hori, Y. \& K. Arai, 1971. Studies on the effect of day and night temperature on the growth of vegetable crops. I. Growth of young plants of tomato and cucumber affected by day and night temperature and its relation to yield and growth habit of plants after transplanting. Bull. Hort. Res. Sin, Hiratsuka Kanagawa, Ser. A 10: 206-227.

Lint, P. J. A. L. de \& G. Heij (in press). Night temperature and flower abortion of glasshouse cucumber. Neth. J. agric. Sci.

Lint, P. J. A. L. de \& G. Heij, 1981. Glasshouse cucumber, effects of planting date and night temperature on flowering and fruit development. Acta Hort. 118: 123-134.

Lorenz, H. P., 1980. Modelluntersuchungen zur Klimareaktion von Wachstumskomponenten am Beispiel junger Salatgurkenpflanzen (Cucumis sativus L). Ein Beitrag zur Temperaturführung in Gewächshäusern. Dissertation, University of Hannover, pp. 138.

Miller, C. H. \& S. K. Ries, 1958. The effect of environment on fruit development of pickling cucumbers. Proc. Am. Soc. hort. Sci. 71: 475-479.

Vooren, J. van de, 1975. A computer for crop research and climate control in glasshouses. Acta Hort. 51: $169-174$.

Vooren, J. van de, 1977. A minicomputer for glasshouse climate control and data analyse. Journal A $18(2): 97-98$

Vooren, J. van de \& R. Koppe, 1975. The climate glasshouse at Naaldwijk. Neth. J. agric. Sci. 23: 238-247.

Vooren, J. van de, P. J. A. L. de Lint \& H. Challa, 1978. Influence of varying night temperatures on a cucumber crop. Acta Hort. 87: 249-255. 